\title{
The Comparison of Chinese and Western Table Manners
}

\author{
Yanye Li \\ School of Foreign Languages Xinxiang University , Henan Xinxiang , China \\ 522851148@qq.com
}

Keywords: Table manners culture, Diet culture, cultural conflicts, Cross-cultural communication

\begin{abstract}
Chinese and western because of different social and cultural, historical and cultural and social background of influence, resulting in two different cultures of generation, table manners culture industry. Through the comparative study of Chinese and western table manners, we know the differences between Chinese and western table manners, and know how to avoid cultural conflicts in cross-cultural communication when we communicate with others.
\end{abstract}

\section{Chinese Table Manners}

Comprehending the etiquettes. For many westerners, the Chinese dinner table is quite unique and complex. At the Chinese table, you can not find forks or knives. The Chinese host makes great, sweeping arm movements that go over large sections of the table passing over food. The scene is fantastic, but it leaves the foreigners at a loss for what to do and how to do. As for eating, our Chinese people usually did it quietly in the past. There was no eating noises allowed to make, and everything must be done as quietly as they could. Therefore, people had to eat with their mouths closed. Perhaps, to make a "smacking" noise was the worst offence behaves. While they are drinking soup, wine or any other kinds of liquid, "slurping" was also forbidden. If any sound whatever was created by our intake of food or beverage, it constituted bad manners! Of course, it was unthinkable to speak with one's mouth full of food, so speaking only occurred before or after one had taken in food and swallowed it. But nowadays, you can see this scene when you are attending a formal party.

How one sits at the table is also prescribed. One is to sit up straight with the recessive hand (usually the left) in one's lap holding a napkin while the dominant hand (usually the right) holds the fork or spoon. The only time one can have both hands on the table is when he is using a knife to cut something, but as soon as the cutting is finished, the recessive hand should go back to the lap. Also, elbows are not allowed on the table. Therefore, one props the arm against the edge of the table just below the elbow. One should ask someone sitting near it to give it to you instead of reaching for any food on the table and stand up for the food. An American said:” In my time in China, I have come to enjoy Chinese table manners far more than those prescribed by my own culture, but for many it is impossible to adjust." So, for the foreigners, the best way is to ask your guest questions to find out the differences and try your best to adjust them.

Handling the taboos. All of the people know that China has a long history, traditionally speaking, there are many taboos at Chinese tables, but these days not many people pay attention to them. However, there are a few things to keep in mind, especially if you are a guest at a private home. The author will list some taboos so as to help the readers to behave more properly and politely.

1) Don't stick your chopsticks upright in the rice bowl. Instead, lay them on your dish. The reason for this is that when somebody dies, the shrine to them contains a bowl of sand or rice with two sticks of incense stuck upright in it. So if you stick your chopsticks in the rice bowl, it looks like this shrine and is equivalent to wishing death upon a person at the table!

2) Make sure that the spout of the teapot is not facing anyone. It is impolite to set the teapot down where the spout is facing towards somebody. The spout should always be directed to where nobody is sitting, usually just outward from the table. 
3) Don't tap on your bowl with your chopsticks. Beggars tap on their bowls, so this is not polite. Also, in a restaurant, if the food is coming too slow people will tap their bowls. If you are in someone's home, it is like insulting the cook.

4) The napkins should be laid on the knee, the elbows should close to the body.

5) Everyone should make preparation before the host or the hostess announced the beginning of the meal.

6) You should let the lady on your right side begin first.

There are much more rules, It is impossible for the author to list them all. Anyway, what the readers should do is to pay much attention to your behavior and try your best to act more properly.

\section{Western Countries' Table Manners}

People's attitude towards western countries' table manners. In order to do the research, the author designed a questionnaire to investigate the understanding of western countries' table manners .The author distributed 200 questionnaires in our campus; all together I collected 175 back. According to result of the research, Majority of university students don't know the table manners well.50\%just know some of our Chinese table culture including how to behave politely at the table, how to toast .etc. But more than $70 \%$ students don't know how to lay the tables, how to use the knife and fork, and how to speak and behave properly and politely at the western countries' table. For the reason is that they think it's unnecessary to know it because they wouldn't have many chances to communicate with the foreigners, let alone eat with them. It's true that not every university student has the opportunities to contact with the foreigners because the foreign teachers in one campus are limited. Being university students, they prefer to pay much attention to their majors rather than learn English. For this reason, they don't think knowing the table manners of westerners matters a lot. As we all know, China has entered the WTO, we encounter the opportunities as well as challenges, and we should keep our pace with the development of globalization and face the challenges bravely. Eating together is one of the most efficient ways for intercommunion. Through the research of this subject, which entitled with "The comparison of the table manners between Chinese and the Westerners", We appeal Chinese people treat the English subject and western culture with a right attitude, and deal with The relationship between the mother language and target language properly. Being student of English, we should not only master the communicative function of the target language, but also comprehend the trans-cultural communication, for culture is knowledge's distillation. Only if we understand the cultural background of the target language, can we have the motivation to learn English language.

Because of the globalization, today, more and more foreigners came to China for work, for traveling. In this situation, more and more international conferences hold in China, not only in the State Department, but also some common places, such as campus, Multinational Corporation, etc. Not complete with the development of society and economy, we will have more and more chances to contact with foreigners when we get a job. Therefore, it's more important for the Chinese people to know the western countries' table manners

Knowing the taboos. It is the common sense of the Europeans and Americans to dress formally when they are attending a party. You should sit from the left side of the chair and do remember that "lady first!"

The napkin should be laid on the knees, usually you should not round the neck with the napkin, it is not proper.

Do not make any noise when you are drinking soup or eating.

Do remember that use your right hand to hold the knife and left hand to use the fork to take food.

Do not fork some food to eat but plow them up to eat.

Do not stand for the foods, it is not polite.

Do not wave the knife and fork in your hand, it is impolite. If you want to talk with somebody else, just put down the table wares first and then you can talk with them.

It is not proper to keep silence all the time at the table, but it doesn't meant you can keep up a constant flow of words. 
In a word, you must be careful. After all, these two kinds of cultures are different and we should adopt the others' custom so that they can respect ours.

\section{The Reason of Comparison between Chinese and Western}

The Impact of Individual's Personality on Etiquette. Oriental culture advocate the spirit of collectivity and team and individual relies much on his collectivity or team, whereas western culture advocate the concept of independence and individual freedom. For example, in Chinese people's concept of self-cultivation, regulating the family, governing the country and the world, character is of crucial importance, which is based on his concern for the country, love for the team, harmony of his family and interpersonal relationship. If he only cares his own interest, his character would be devalued greatly.

In the United States, people have a strong legal concept. They advocate individual liberty, do what they want to do and do not want to be interfered by government, church, or any other organization. At home, children grow up with the concept of self-reliance. Young people always want to be independent as early as possible in order to get rid of their parents. They do not want over-reliance on their family and parent; otherwise, they will lose their freedom as well as the respect from other people. Chinese culture is totally different with the American's on this point. For Chinese people, family is the most important collectivity. Chinese parents cherish their children so much that they even want to do everything for them. For example, when their children become adults and get married, they would provide them with a profile wedding ceremony. When their children have children, they would take care of their grandchildren rather than enjoy an ease and peaceful old life. They put all their hopes on their children and take too much care of them, resulting in theirs poor self-care ability. Even in today's transition from planned economy to market economy, the workers of state-owned enterprises extremely reluctant to lost their permanent job. The dependence is the heritage of Chinese traditional culture and has a far-reaching impact on the cultural concept of modern Chinese people.

The Impact of the Concept of Hierarchy on Etiquette. Oriental culture has a strong concept of hierarchy, and it is impolite to cross the class no matter it is in an organization, or at home. Although in reason, the concept of hierarch has been eliminated, it still poses impact on oriental culture in reality. China's planned economy once divided enterprises into different classes. Though not very universal, the concept of hierarch exits in oriental society here and there.

Most of Western countries advocate the concept of equality, except the United Kingdom and a few other countries that have a hereditary aristocracy and guarded hierarchy system. In American families, people pay no attention to class, they have a mutual respect between parents and children, and they can call each other's name directly. They have a weak sense of family and do not want to make too much sacrifice for their family.

The Impact of the Difference of Interpersonal Relationship on Etiquette. Both oriental and western culture attributes great attention to interpersonal relationship, but there is obvious difference in the ideas and ways of dealing with it. Chinese people are very hospitable to their friends and they have nothing secret to keep from their friends about their age, occupation, income, marriage and children. In Western countries, people pay special attention to privacy; they have no any interest in other people's privacy and private life and also do not want to be interfered. Chinese people will directly ask the price of the item of their friends because in Chinese eyes, price simply means value of the goods. Whereas in the eyes of Westerners, if one asks the price of his friend' goods, his friend may think that he wants to know his economic situation, which belongs to privacy and not allowed to ask.

The Impact of Gender and Age on Etiquette. In oriental culture, men are usually highly respected, which is mainly due to the impact of the concept that men enjoy more respect in the feudal society. Whereas in modern society, oriental culture also argues the equality between men and women, but that is not always the case. Men still enjoy more superiority than women in many situations and the phenomenon that women are discriminated still exits. In Western countries, the 
respect for women is a traditional custom and "Ladies First" is one of the principles of Western social activities. Men have to take care of women in any public places.

As the inter-generational relation, Chinese people honor and respect the elderly particularly. In Western countries, because of the concept of independence of children, many elderly people often feel lonely and bleakly in their later life.

\section{Conclusion}

There are abundant and extensive table manners forming in the east, while there are exquisite and distinctive table manners forming in the west. Table manners are part of table culture. Different table manners embody the different cultures. Manner is the character of a person, while culture is the soul of a nation. As a custom, table manners exist all over the world, determined by national culture, which raises many differences. The cultural differences not only take place between countries, but also exits between different areas of one country. In face of these differences, we should comprehend and respect their habits and culture. According to the traditional culture, the Chinese are strict with oneself and lenient towards others. "Worry about what others worry, and think about what others think" is their attitude towards life. When we face the different cultures, what we should do first is to show respect for others. In the cross-culture communication, people begin with know about each other, which make them understand mutually. Then people exchange more, and make some explanations to reduce the misunderstanding. When in Rome, do as the Romans do. This is a good way to cope with difference. A guest should suit the convenience of the host. This way, will be fewer misunderstandings. The communications between China and the West becom easier.

\section{References}

[1] Craig Claiborne.Elements of Etiquette.A guide to Table Manners in an Imperfect World.New York:Warner Books,1992.

[2] Judith Martin.Miss Manner’s Guide for the Turn of Millennium.New York:Pharos Books,1989.

[3] Larry A.Samovar \& Richard E.Porter.Communication between Cultures.1995.

[4] Margaret Visor.The Ritual of Dinner of the Origins, Evolution, Eccentricities, and Meaning of Table Manners.New York:Penguin Books,1991. 